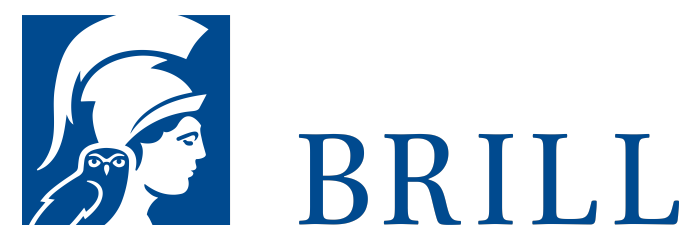

\title{
Tatort "Troia"
}

Geschichte - Mythen - Politik

Author: Frank Kolb

Gab es ein Troia? Nein! Gab es einen Troianischen Krieg? Nein! Auswandernde Griechen haben eine im Mutterland entstandene Sage an einer bronzezeitlichen RuinenstÃatte im nordwestlichen Kleinasien verankert, deren damaligen Namen wir nicht kennen und die Schliemann ausgegraben hat. Viel bedeutender als jener Ort sind die Darstellung des Mythos $\hat{A}^{\prime}$ in Homers Ilias und seine spãatere politische Instrumentalisierung.

Frank Kolb bietet ein faszinierendes, aber zugleich entlarvendes Bild von Â»TroiaÂ « und der Troia-Forschung. Er zeigt, dass das Bem $\tilde{A} 1 / 4$ hen, den Mythos mit dem Spaten des Arch ̃̃ oologen als Geschichte zu erweisen, methodisch verfehlt und erfolglos war und zu wissenschaftlich fragw Ã $1 / 4$ rdigen Vorgehensweisen fã $1 / 4$ hrte. Der Â»Schicksalsh $\tilde{A} 1 / 4$ gel der Arch $\tilde{A}{ }_{0}$ ologie $\hat{A}$ « wurde zu einem Skandalh $\tilde{A} 1 / 4$ gel.

Dieses allgemeinverst Ã andlich und spannend geschriebene Buch prÃasentiert die mit dem Troia-Mythos, der homerischen Ilias und den Ausgrabungen seit Schliemann verbundenen Probleme auf dem neuesten Stand der Forschung. Es bettet die Troia-Frage in die Frã $1 / 4$ hgeschichte des Ã „g ̃̃ disraumes, Anatoliens und des Vorderen Orients ein. Es zeigt ferner, wie der Troia-Mythos durch die Jahrhunderte bis heute f $\tilde{A} 1 / 4 \mathrm{r}$ politische, gesellschaftliche und wirtschaftliche Zwecke instrumentalisiert worden ist.

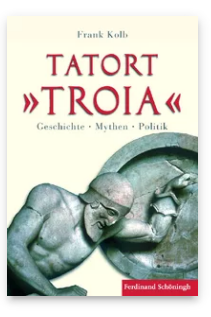

Pages: 320

Seiten, $13 \mathrm{~s} / \mathrm{w}$ und 14 farb. Abb.

Language:

German

Subjects:

Ancient History,

Classical Studies

Publisher: Brill |

SchÃ ๆningh

E-Book (PDF)

Released online: $26 \mathrm{Jul} 2013$

ISBN: $978-3^{-}$

657-77009-0

List price

USD $\mathrm{A} \$ 52.00$

Hardback

Publication date:

15 Sep 2010

ISBN: $978-3^{-}$

506-77009-7

List price

USD 
For more information see brill.com

Order information: Order online at brill.com +44330 333 0049 | customerservices@brill.com Submission information: brill.com/authors

Titles published by Brill | Fink, Brill | mentis or Brill | Schöningh: +49(o)715413279216| brill@brocom.de 